\title{
CORRESPONDENCE
}

\section{Response to comment on subacute post-traumatic ascending myelopathy: a literature review}

Spinal Cord Series and Cases (2017) 3, 17014; doi:10.1038/ scsandc.2017.14; published online 27 April 2017

We are glad to hear that Dr Miller \& Dr Ahmad show great interest in our review: Subacute post-traumatic ascending myelopathy: a literature review. ${ }^{1}$

As many articles have mentioned, subacute post-traumatic ascending myelopathy (SPAM) is defined as neurological deterioration involving four or more vertebral segments above the initial injured site within the first few weeks. In our case, we suspect that a durotomy was indicated for improving respiratory failure caused by ascending myelopathy. Our purpose for reporting is just to remind the readers that SPAM is life-threatening and difficult to treat.

In the case from Dr Miller \& Dr Ahmad, SPAM developed in a young man after mild spinal cord injury by gunshot, ${ }^{1}$ which is similar to Dr Visocchi's case who had no neurological dysfunction after a neck gunshot injury, but unfortunately neurological deterioration occurred after $9 \mathrm{~h}^{2}$ A different mechanism of injury may exist in gunshot injury.

\section{COMPETING INTERESTS}

The authors declare no conflict of interest.

\author{
Jian Zhang ${ }^{1}$ and Guangshun Wang ${ }^{2}$ \\ ${ }^{1}$ Department of Orthopedic Surgery, \\ Baodi District, Tianjin, China and \\ ${ }^{2}$ Department of Thoracic Surgery, \\ Baodi District, Tianjin, China \\ Correspondence: J Zhang (zhangjbdyy@126.com)
}

\section{REFERENCES}

1 Miller BA, Roy AK, Boucher AB, Pradilla G, Ahmad FU. Subacute posttraumatic ascending myelopathy after an incomplete spinal cord injury from a gunshot wound to the spine: case report and review of the literature. World Neurosurg 2016; 88: 687.e13-7.

2 Visocchi M, Di Rocco F, Meglio M. Subacute clinical onset of postraumatic myelopathy. Acta Neurochir 2003; 145: 799-804. 